Tema: Corrosão

\title{
CORROSÃO NAS REGIÕES DE INSTABILIDADE PLÁSTICA NO AÇO INOXIDÁVEL AUSTENITICO ALTO NITROGÊNIO ISO 5832-9*
}

\author{
José Helio Sobrinho' \\ Eden Santos Silva ${ }^{2}$ \\ Samuel Filgueiras ${ }^{3}$ \\ Jean Roberto ${ }^{4}$ \\ Gedeon Silva Reis ${ }^{5}$ \\ Jose Manuel Rivas Mercury ${ }^{6}$
}

\section{Resumo}

O aço inoxidável austenítico alto nitrogênio ISO 5832-9 tem sido promissor na manufatura de próteses ortopédicas com resistência mecânica e de corrosão superiores a do aço tradicional ASTM F-138. Pesquisas recentes têm mostrado que esta liga apresenta resultados peculiares, tais como alta resistência mecânica, resistência à corrosão e presença de partículas de segunda fase (Fase Z) na matriz. Entretanto, não se sabe como se dá a correlação mecânica-microestrutural e de taxa de corrosão em regiões de processabilidade industrial desta liga na conformação a quente de peças. No presente trabalho, ensaios sob torção a quente isotérmico contínuo e interrompidos foram realizados após tratamento térmico de solubilização a $1.200^{\circ} \mathrm{C}$, por $300 \mathrm{~s}$ com intervalos de temperatura variando entre $1.000^{\circ} \mathrm{C}$ e $1.200^{\circ} \mathrm{C}$ com taxa de deformação variando entre 0,05 e $5 \mathrm{~s}^{-1}$, para investigar a trabalhabilidade e a taxa de corrosão sob tensão desta liga com aplicação da técnica de espectroscopia de impedância eletroquímica e caracterização microestrutural, conduzida por microscopia óptica e varredura. Os resultados mostram que a tensão de escoamento é sensível aos parâmetros de deformação. O pico de tensão diminui com o aumento da temperatura e redução da taxa de deformação com alta taxa de recuperação dinâmica com grãos alongados, gerando regiões de acúmulo de tensão. Essas regiões de instabilidade plástica apresentam grau de corrosão superior em relação às amostras como-recebidas. As regiões de alta temperatura e baixa taxa de deformação apresentam boa trabalhabilidade com microestrutura final refinada com grãos recristalizados dinamicamente.

Palavras-chave: Aço inoxidável; Instabilidade plástica; Mapa de processamento; Corrosão.

\section{Abstract \\ PLASTIC INSTABILITY IN ISO 5832-9 HIGH-NITROGEN AUSTENITIC STAINLESS STEEL}

ISO 5832-9 high-nitrogen austenitic stainless steel has shown promising results in the fabrication of temporary and permanent orthopedic prostheses, exhibiting better mechanical strength and corrosion resistance than the traditional ISO 5832-1 (ASTM F-138) steel. Recent studies have revealed that this alloy possesses unique properties, such as high mechanical strength and corrosion resistance and the presence of second phase particles ( $Z$ phase) in the matrix. However, it is not known how the microstructural and mechanical properties and the corrosion rate are correlated in regions of industrial processability of this alloy during hot forming. In this study, continuous and interrupted isothermal hot torsion tests were performed after solubilization heat treatment at $1,200^{\circ} \mathrm{C}$ for $300 \mathrm{~s}$, with temperature intervals varying from $1,000^{\circ} \mathrm{C}$ to $1,200^{\circ} \mathrm{C}$ and strain rates ranging from 0.05 to $5 \mathrm{~s}^{-1}$. The purpose of these tests was to investigate the alloy's workability and stress corrosion rate by means of electrochemical impedance spectroscopy (EIS) and to characterize its microstructure by optical and scanning electron microscopy. The results indicate that the yield stress is sensitive to the strain parameters. The peak stress decreases with increasing temperature and decreasing strain rate, with a high rate of dynamic recovery, with elongated grains generating areas of stress build-up. These regions of plastic instability present a higher degree of corrosion than as-received samples. The regions of high temperature and low strain rate exhibit good workability with a refined final microstructure of dynamically recrystallized grains.

Keywords: Stainless steel; Plastic instability; Processing maps; Corrosion.

1 Físico, Mestre, Aluno, Programa de Pós Graduação em Eng. dos Materiais, Departamento de Eng. Mecânica, Instituto Federal do Maranhão (IFMA), São Luis, MA, Brasil.

2 Físico, Doutor, Professor, Programa de Pós Graduação em Eng. dos Materiais, Depto. Eng. Mecânica, IFMA, São Luis, MA, Brasil.

3 Físico, Mestre, Professor, Programa de Pós Graduação em Eng. dos Materiais, Depto. Eng. Mecânica, IFMA, São Luis, MA, Brasil.

4 Eng. Mecânico, Dr., Professor, Programa de Pós Graduação em Eng. dos Materiais, Depto. Eng. Mecânica, Universidade Federal do Maranhão (UFMA), São Luis, MA, Brasil.

5 Eng. Civil, Doutor, Professor, Programa de Pós Graduação em Eng. dos Materiais, Depto. Eng. Mecânica, IFMA, São Luis, MA, Brasil.

6 Químico Industrial, Eng. Mecânica, Doutor, Professor, Programa de Pós Graduação em Eng. dos Materiais, Depto. de Eng. Mecânica, IFMA, São Luis, MA, Brasil.

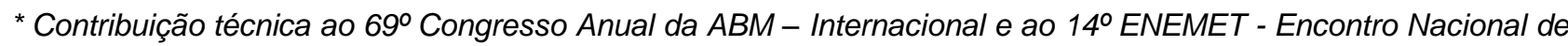
Estudantes de Engenharia Metalúrgica, de Materiais e de Minas, 21 a 25 de julho de 2014, São Paulo, SP, Brasil.
} 


\section{INTRODUÇÃO}

Os aços inoxidáveis austeníticos apresentam boa resistência à corrosão e combinação adequada de propriedades mecânicas para muitas aplicações industriais. No entanto, ao serem utilizados como implantes ortopédicos podem apresentar vários problemas, tais como, suscetibilidade à corrosão localizada, quando em contato com fluidos e tecido humano. Além de apresentar regiões de instabilidade plástica dentro das condições de processamento industrial das peças.

O aço inoxidável austenítico alto nitrogênio ISO 5832-9, especificado pela norma ISO $5832-9$ com composição típica de $22 \mathrm{Cr}-10 \mathrm{Ni}-2.5 \mathrm{Mo}-0.4 \mathrm{Nb}-0,35 \mathrm{~N}$, tem sido promissor na confecção de próteses ortopédicas temporárias e permanentes com propriedades superiores a do aço utilizado tradicionalmente ISO 5832-1 (ASTM F138) [1]. Pesquisas recentes têm mostrado que esta liga apresenta resultados peculiares, tais como, alta resistência mecânica, resistência à corrosão e presença de partículas de segunda fase (Fase Z) na matriz [2,3]. Entretanto não se sabe como se dá a correlação mecânica-microestrutural e de taxa de corrosão em regiões de processabilidade industrial desta liga na conformação a quente de peças ortopédicas.

Novas pesquisas evidenciam que a degradação de implantes ortopédicos a partir de ligas de aços inoxidáveis austeníticos utilizados em implantes, como AISI 316, AISI 316LVM, ASTM F-138 e o ISO 5832-9, no interior do corpo humano é indesejável por algumas razões, tais como: o processo de degradação resultante da ação corrosiva da liga implantada que pode prejudicar a integridade estrutural do implante e também os produtos liberados no processo de degradação que pode culminar em reações biológicas adversas ao paciente, onde a ação combinada de processos eletroquímicos da corrosão e os esforços mecânicos podem acelerar o processo de degradação localizada, afetando sítios aleatórios na superfície do metal através da corrosão por pites [4].

No caso dos aços inoxidáveis austeniticos sua alta resistência a corrosão deve-se a formação de um filme superficial protetor de óxido de cromo, denominado filme passivo que, aderente a superfície do metal, inibe o processo de corrosão [5]. Imediatamente após a quebra, o metal base desprotegido entra em contato com o meio agressivo, promovendo a sua dissolução até que ocorra a reconstituição da camada danificada ou repassivação. Resultados similares foram observados por Giordani, E.J [2,3], onde a maior resistência a corrosão no aço ISO 5832-9 é principalmente atribuído ao aumento da estabilidade do filme passivo, favorecida pela presença do nitrogênio em solução sólida na matriz e elementos de liga que promovem o aumento de resistência a corrosão por pites nos aços inoxidáveis austeniticos.

Durante a manufatura dos implantes, os materiais metálicos passam por um processo de forjamento a quente com a evolução da microestrutura relacionada com os fenômenos de amaciamento dinâmico que desempenham um papel importante na determinação da microestrutura e propriedades finais da liga. Os mecanismos microestruturais sob deformação a quente em metais e ligas são geralmente governados pela energia de falha de empilhamento (EFE) e tem seu comportamento mecânico controlado por três fenômenos: encruamento (HW), recuperação dinâmica (DRV) e recristalização dinâmica (DRX) que são importantes mecanismos de controle microestrutural e mecânico na trabalhabilidade a quente [6,7].

Em alguns materiais com alta EFE, tais como Alumínio (Al), $160 \mathrm{~mJ} / \mathrm{m}^{2}$, o balaço entre o encruamento e recuperação dinâmica é expresso por um patamar na curva

\footnotetext{
* Contribuição técnica ao 69ํ Congresso Anual da ABM - Internacional e ao 14 ENEMET - Encontro Nacional de Estudantes de Engenharia Metalúrgica, de Materiais e de Minas, 21 a 25 de julho de 2014, São Paulo, SP, Brasil.
} 


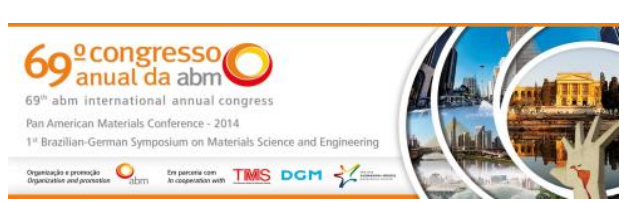

de escoamento plástico [8,9]. Entretanto, os materiais com baixa e moderada EFE, tais como os aços inoxidáveis austeníticos, por exemplo, o aço AISI 304L a EFE é aproximadamente de $18 \mathrm{~mJ} / \mathrm{m}^{2}$, enquanto no aço AISI 305 é cerca de $34 \mathrm{~mJ} / \mathrm{m}^{2}$, no aço AISI 310 S cerca de $94 \mathrm{~mJ} / \mathrm{m}^{2}$ e no aço AISI 316 cerca de $78 \mathrm{~mJ} / \mathrm{m}^{2}$ [9]. A contribuição de $\mathrm{Ni}, \mathrm{Cr}, \mathrm{Mn}$ e Mo para a EFE da matriz de um aço inoxidável austenítico foi estimada e a EFE para o aço ISO 5832-9 foi calculada como 68,7 $\mathrm{mJ} / \mathrm{m}^{2}$ [2], a cinética de recuperação dinâmica é lenta, e a recristalização dinâmica é iniciada numa condição crítica de acúmulo de energia de deformação, associada com o amaciamento na curva de escoamento plástico. Assim o efeito da recristalização dinâmica nos parâmetros mecânicos, microestruturais e de corrosão em termos das condições de trabalho são de suma importância, pois dependem da composição química do material, do modo de deformação e das condições de deformação.

Essas condições de deformação usuais no processamento metalúrgico determinam as regiões de melhor trabalhabilidade, que são representadas através de mapas de processamento, desenvolvidos utilizando os sistemas de engenharia, a mecânica dos meios contínuos, os princípios da termodinâmica de processos irreversíveis e a aplicação dos critérios de escoamento plástico [10,11]. Essas regiões estão correlacionadas com os processos microestruturais específicos que ocorrem durante o trabalho a quente, onde as melhores regiões para processar o material são identificadas no domínio de recristalização dinâmica.

As informações dos mapas de processamento podem ser efetivamente integradas com o projeto e otimização dos processos industriais das ligas ortopédicas. Enquanto que a temperatura e a taxa de deformação no domínio de máxima trabalhabilidade são escolhidos como parâmetros de processo otimizados que deve ser controlados de tal modo que os valores locais de temperatura e taxa de deformação não entrem nos regimes indesejáveis como fluxo de instabilidade [12], torna-se necessário encontrar um domínio seguro a taxas mais elevadas de tensão que aumenta a produtividade.

Devido a complexidade microestrutural e de utilização deste material é importante entender o comportamento constitutivo deste material caracterizando suas propriedades finais e compreendendo a microestrutura desenvolvida durante a deformação dentro das regiões de trabalhabilidade para se chegar aos melhores parâmetros de processamento. O objetivo do trabalho é avaliar o grau de corrosão nas regiões de trabalhabilidade a quente na linha de processamento industrial dessa liga, onde trabalhos recentes têm evidenciado a presença de regiões de instabilidade plástica.

\section{MATERIAIS E MÉTODOS}

O material usado nesta pesquisa foi o aço inoxidável alto nitrogênio, ISO 5832-9, cuja composição química é dado na Tabela 1, fornecido pela Villares Metals, São Paulo, Brasil. Esta liga comercial foi previamente laminado a quente com barras de diâmetro $20 \mathrm{~mm}$, recozidos em $1030^{\circ} \mathrm{C}$ durante 60 min e resfriado em água. Os ensaios mecânicos foram realizados em uma máquina de torção a quente computadorizada modelo TM-IV no laboratório de engenharia mecânica (DMM), do Instituto Federal do Maranhão (IFMA). Os corpos de prova foram usinados com diâmetro e comprimento úteis de $10 \mathrm{~mm}$ na seção central de menor calibre, foram aquecidas em um forno por radiação infravermelha acoplado na máquina de

\footnotetext{
* Contribuição técnica ao $69^{\circ}$ Congresso Anual da ABM - Internacional e ao 14ํㅡㄹ ENEMET - Encontro Nacional de Estudantes de Engenharia Metalúrgica, de Materiais e de Minas, 21 a 25 de julho de 2014, São Paulo, SP, Brasil.
} 
ensaios. A temperatura foi medida usando termopar tipo $\mathrm{K}$ (Cromel-Alumel) encaixado no corpo de prova.

Tabela 1. Composição quimica do aço inoxidável austenitico ISO 5832-9.

\begin{tabular}{cccccccccccc}
\hline $\mathbf{C}$ & $\mathbf{S i}$ & $\mathbf{M n}$ & $\mathbf{N i}$ & $\mathbf{C r}$ & $\mathbf{M o}$ & $\mathbf{S}$ & $\mathbf{P}$ & $\mathbf{N}$ & $\mathbf{C u}$ & $\mathbf{N b}$ & $\mathbf{F e}$ \\
\hline 0,035 & 0,37 & 4,04 & 10,6 & 20,3 & 2,47 & 0,001 & 0,022 & 0,36 & 0,06 & 0,29 & bal. \\
\hline
\end{tabular}

Os dados foram coletados por meio de um programa que impõe testes paramétricos como temperatura, taxa de deformação, tempo de espera e quantidade de esforço, segundo critérios de Von Misses. As amostras foram aquecidas desde a temperatura ambiente até uma temperatura de imersão de $1200^{\circ} \mathrm{C}$ a uma taxa de $10^{\circ} \mathrm{C} / \mathrm{s}$, mantida a esta temperatura durante $600 \mathrm{~s}$, arrefeceu-se para a temperatura de teste a uma taxa de $2^{\circ} \mathrm{C} / \mathrm{s}$, realizada durante $30 \mathrm{~s}$, e finalmente tensionadas isotermicamente nas condições desejadas ou até a fratura da amostra. Estes testes foram efetuados a partir dos mapas de processamento do trabalho desenvolvido por Silva, E. S. [13], em condições que descrevam regiões de instabilidade. Para correlacionar a microestrutura com as condições de deformação, as amostras foram imediatamente arrefecida a água após a deformação aplicada. Após os procedimentos metalográficos padrão, a microestrutura foi condicionada a um ataque eletroquímico com ácido nítrico (65\%) e em seguida examinada por microscopia óptica e varredura.

Para os ensaios eletroquímicos de corrosão foi empregado um potenciostato Autolab (Eco Chemie), Mod PGSTAT30, conjugado a um analisador de freqüência, FRA 4.9 e acoplado a um microcomputador. Os eletrodos de trabalho consistiram de discos do aço inoxidável ISO 5832-9 retirados da parte útil do corpo de prova após os ensaios de torção, com área de $0,78 \mathrm{~cm}^{2}$ exposta à solução $0,9 \%$ de $\mathrm{NaCl}$ a $25^{\circ} \mathrm{C}$, os quais foram previamente lixados com lixa comum de carbeto de silício ( $\mathrm{SiC}$ ), de granulometria de 300, 400 e 600, lavados com água destilada e álcool etílico e secos em jato de ar quente. Os ensaios eletroquímicos foram realizados utilizando um esquema clássico de três eletrodos, com um eletrodo de calomelano saturado (ECS) e um eletrodo de platina, funcionando como referência e contra-eletrodo, respectivamente. Os diagramas de impedância foram obtidos no intervalo de frequência entre $50 \mathrm{kHz}$ e $10 \mathrm{MHz}$ com amplitude de perturbação de $10 \mathrm{mV}$. Todos os ensaios foram realizados no potencial de circuito aberto a intervalos de tempo iguais a $30 \mathrm{~min}$. Todas as curvas foram levantadas pelo menos três vezes e as medidas foram realizadas com eletrodo parado.

Para investigar a evolução microestrutural durante a deformação a quente, foram realizados ensaios isotérmicos que foram interrompidos em diferentes níveis de deformação. Sempre, imediatamente após a interrupção da deformação, as amostras eram resfriadas bruscamente em água. Foram escolhidas diferentes condições de deformação, segundo o trabalho desenvolvido por Silva, E.S [13], com mapas de processamento, evidenciando as condições de trabalhabilidade, Tabela 2. Com a finalidade de verificação da heterogeneidade microestrutural, instabilidade plástica e corrosão, esta caracterização microestrutural foi feita por microscopia ótica e foi utilizado um ataque eletroquímico com ácido nítrico $\left(\mathrm{HNO}_{3}\right)$ a $65 \%$ entre 10 e $120 \mathrm{~s}$ sob corrente $1,0 \mathrm{~A} / \mathrm{cm}^{2}$. Esse ataque foi utilizado para revelar contornos de grão, contornos de maclas, regiões de instabilidade plástica e contagem do tamanho médio de grão.

\footnotetext{
* Contribuição técnica ao 69ำ Congresso Anual da ABM - Internacional e ao 14ํㅡㄹ ENEMET - Encontro Nacional de Estudantes de Engenharia Metalúrgica, de Materiais e de Minas, 21 a 25 de julho de 2014, São Paulo, SP, Brasil.
} 


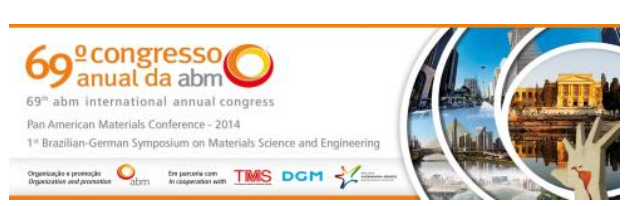

Tabela 2. Condições escolhidas para realização dos ensaios de torção isotérmicos interrompidos, segundo os mapas desenvolvidos por Silva, E.S [13]

\begin{tabular}{ccccc}
\hline Amostras & $\boldsymbol{\varepsilon}$ & $\mathbf{T}\left({ }^{\circ} \mathbf{C}\right)$ & Taxa $\left(\mathbf{s}^{-\mathbf{1}}\right)$ & Domínio \\
\hline A1 & 0,5 & 1050 & 0,05 & Inst. \\
A2 & 0,75 & 1000 & 1,0 & Inst. \\
A3 & 1,3 & 1000 & 0,1 & Inst. \\
A4 & 2,0 & 1000 & 0,1 & Inst. \\
A5 & 4,0 & 1050 & 0,5 & Trab. \\
A6 & 2,0 & 1200 & 1,0 & Trab. \\
A7 & 4,0 & 1050 & 0,1 & Trab. \\
\hline
\end{tabular}

\section{RESULTADOS E DISCUSSÃO}

\subsection{Curva de Escoamento Plástico}

A Figura 1 apresenta as curvas de escoamento plástico do aço inoxidável austenítico ISO 5832-9 obtidas através dos ensaios de torção a quente isotérmico em diferentes níveis de deformação similares às do processamento industrial. Notase que as curvas têm a forma típica de materiais que recristalizam dinamicamente. Inicialmente, há uma região de encruamento, com alteração na curvatura conforme o material é deformado. Com o prosseguimento da deformação alcança-se um máximo correspondente ao pico de tensão, para em seguida cair gradualmente para um valor intermediário para grandes deformações. Nestas condições é possível visualizar que as curvas podem ser separadas em três tipos segundo sua forma: (i) amaciamento de tensão após o pico, levando o estado estacionário para grandes deformações; (ii) Amaciamento contínuo, com fluxo localizado; (iii) Curva de escoamento tipo plano, onde a tensão praticamente não varia com a deformação com intensa recuperação dinâmica e redução da taxa de encruamento alcançando uma tensão de saturação.
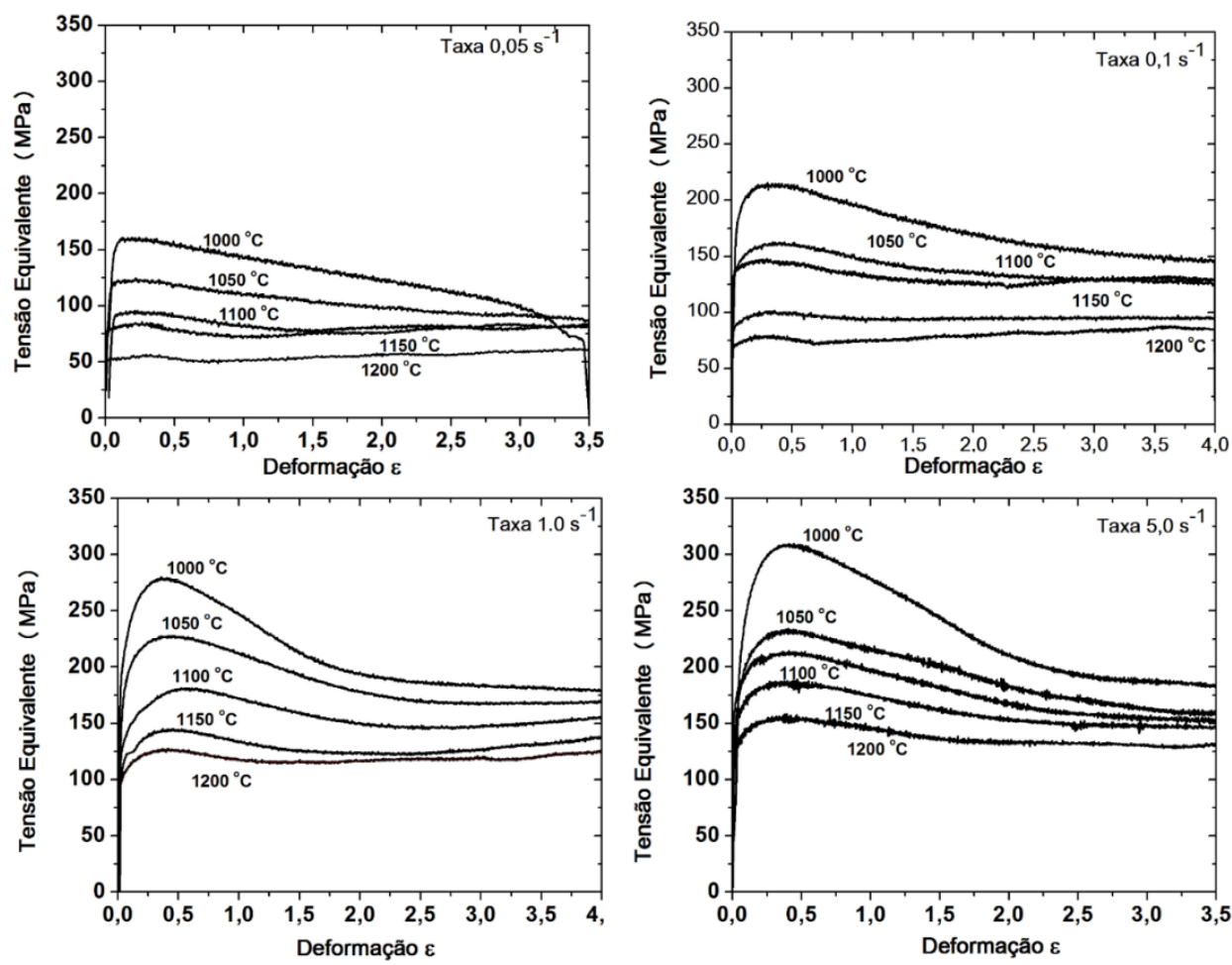

Figura 1. Curvas de escoamento plástico obtidas dos testes de torção a quente isotérmico contínuo do aço ISO 5832-9.

* Contribuição técnica ao 69 Congresso Anual da ABM - Internacional e ao 14ํ ENEMET - Encontro Nacional de Estudantes de Engenharia Metalúrgica, de Materiais e de Minas, 21 a 25 de julho de 2014, São Paulo, SP, Brasil. 
Vê-se nas curvas que o nível de tensão aumenta com o acréscimo da taxa de deformação para uma determinada temperatura e de forma análoga com a redução da temperatura a taxa de deformação constante. Por outro lado, a evolução da quantidade de deformação apresenta comportamentos distintos. Pode-se ver que as curvas determinadas em menores níveis de temperatura e maiores taxas de deformação têm os seus picos de deformações deslocados para a esquerda. Observa-se ainda que após a condição de pico o amaciamento só se completa após grandes deformações. Este aspecto típico de materiais recristalizados dinamicamente deve-se a geração de discordâncias, maclas e bandas de deformação quando o material é deformado a quente aumentando a resistência mecânica com redução na mobilidade das discordâncias [9]. Este aço inoxidável austenitico, ISO 5832-9, apresenta moderada EFE com taxa de aniquilação de discordância menor que a taxa de geração e como consequência há um acúmulo de discordâncias de forma heterogênea, favorecendo a nucleação de novos grãos.

O estado estacionário de tensão foi atingido em todos os experimentos conduzidos em altas temperaturas. Apesar de algumas pequenas diferenças observadas na forma das curvas, com comportamento característico do amaciamento de tensão promovido pela recristalização dinâmica. Em altas temperaturas, a queda de tensão entre a tensão de pico e de estado estacionário é relativamente pequeno, enquanto a queda após o pico é lenta e relativamente maior em temperaturas intermediárias onde fica claro que a extensão do amaciamento promovido pela recuperação dinâmica após o início da recristalização dinâmica afeta a forma da curva.

Pode-se ver que, em altas temperaturas e baixa taxa de deformação, em especial a $0,01 \mathrm{~s}^{-1}$, a parte inicial das curvas de escoamento plástico tem a forma diferenciada das demais. O escoamento plástico inicia em níveis de tensões muito próximos dos valores das tensões de pico, gerando uma região de deformação plástica com taxa de encruamento relativamente baixa. Este comportamento é observado com clareza a 1200,1150 e $1100^{\circ} \mathrm{C}$ com taxa de $0,01 \mathrm{~s}^{-1}$ e a temperatura de $1200^{\circ} \mathrm{C}$ com taxa de $0,5 \mathrm{~s}^{-1}$. Este comportamento pode está associado ao aumento da sensibilidade à taxa de deformação da tensão à temperatura de deformação que está coligado a dependência do nível da EFE com a temperatura. Em alta temperatura o valor da EFE aumenta, com redução do espaçamento entre as discordâncias parciais tornando o processo de recombinação mais fácil, visto que a EFE influencia na escalagem e deslizamento de discordâncias, que são fatores predominantes na trabalhabilidade a quente dos metais.

Este elevado nível de tensão justifica-se pelos altos níveis de tensões necessárias para ocorrência da recristalização dinâmica. Observando as curvas da Figura 1c-d pode-se especular que os maiores níveis desta razão estão associados ao deslocamento para a esquerda das curvas de escoamento plástico. Este deslocamento é imposto por maiores valores da taxa de encruamento, causando assim uma ascensão marcada pela alta energia de ativação térmica retardando o início da recristalização dinâmica. Este nível elevado na energia de ativação leva a um aumento na tensão para início da recristalização, justificado pela presença de precipitados (fase $Z$ ) que aumenta a tensão de atrito da rede cristalina refletindo sobre o limite de escoamento plástico do material e redução na EFE com aumento na eficiência dos contornos de grãos. Analise semi-quantitativas por EDS revelam que esses precipitados são ricos em $\mathrm{Cr}$ e Nb, Figura 2, comprovando a presença da fase $Z$.

\footnotetext{
* Contribuição técnica ao 69ํ Congresso Anual da ABM - Internacional e ao 14 ENEMET - Encontro Nacional de Estudantes de Engenharia Metalúrgica, de Materiais e de Minas, 21 a 25 de julho de 2014, São Paulo, SP, Brasil.
} 

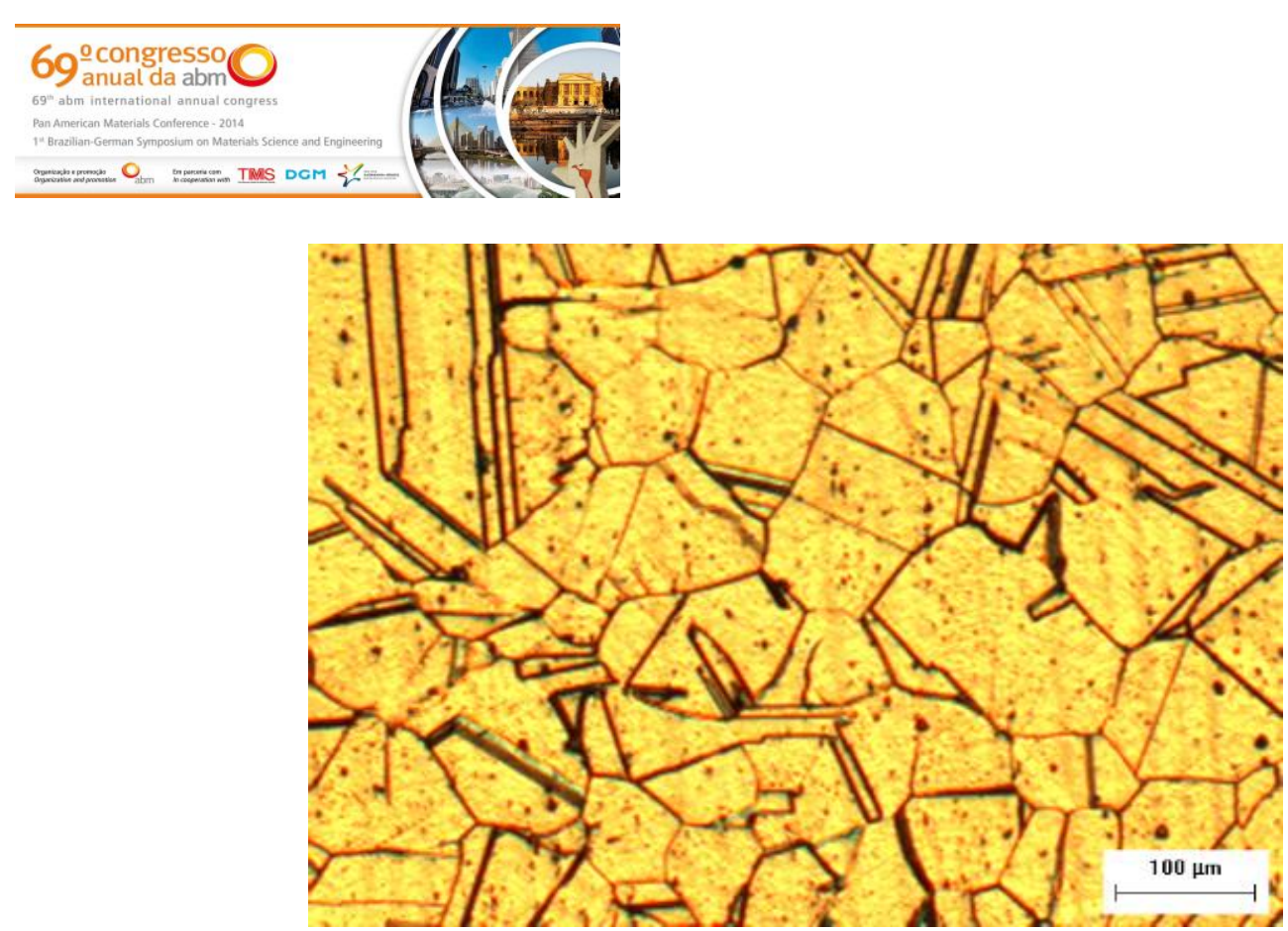

Figura 3. Microestrutura inicial de uma amostra do aço ISO $5832-9$ reaquecida a $1250{ }^{\circ} \mathrm{C}$ e mantida durante 300 s antes de ser resfriada em água.

Para investigar a evolução microestrutural durante a deformação a quente, foram realizados ensaios de torção isotérmicos interrompidos em diferentes níveis de deformação. Sempre, imediatamente após a interrupção da deformação, as amostras eram resfriadas bruscamente em água. Foram escolhidas sete diferentes condições de deformação. As quatro primeiras foram escolhidas nas regiões de instabilidade plástica, segundo os mapas de processamento: $A 1\left(1000{ }^{\circ} \mathrm{C} / 0,05 \mathrm{~s}^{-1} /\right.$ 0,5); $\mathrm{A} 2\left(1000^{\circ} \mathrm{C} / 1,0 \mathrm{~s}^{-1} / 0,75\right)$; $\mathrm{A} 3\left(1000^{\circ} \mathrm{C} / 0,1 \mathrm{~s}^{-1} / 1,3\right)$ e $\mathrm{A} 4\left(1000{ }^{\circ} \mathrm{C} / 0,1 \mathrm{~s}^{-1} / 2,0\right)$, Figura 4.

Nessas condições vê-se que nas deformações próximo ao pico a microestrutura encontra-se deformada e fortemente encruada com grãos alongados e surgimento de novos grãos recristalizados dinamicamente gerados ao longo dos contornos préexistentes, sem qualquer mudança maior no seu tamanho médio. Esta sequência microestrutural sugere que a recristalização se inicia pelo processo de nucleação por colar. Mas embora os novos grãos se formem em tornos dos contornos de grãos antigos, a distribuição dos novos grãos com a evolução da deformação não mantém exatamente a forma típica do processo de nucleação por colar. Vê-se que uma grande concentração de novos grãos se formam em torno de alguns contornos de grãos antigos com deformação plástica localizada, caracterizando-se um processo de fluxo localizado com formação de bandas de cisalhamento adiabático que gera instabilidade plástica no aço com reflexo na forma da curva, Figura 4d, avançando quanto maior a deformação aplicada. Também, vale observar que a microestrutura após grande deformação possui ainda muitos grãos antigos deformados (em forma de panquecas), mostrando que mesmo em sob grandes deformações a recristalização dinâmica ainda não se completou e se da heterogeneamente, mesmo com deformações no estado estacionário de tensões, e o tamanho médio dos grãos recristalizados dinamicamente é maior que o tamanho médio observado nas etapas iniciais, quando prevalece à nucleação com formação de colar.

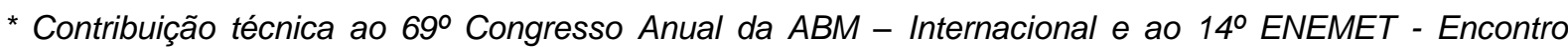
Nacional de Estudantes de Engenharia Metalúrgica, de Materiais e de Minas, 21 a 25 de julho de 2014, São Paulo, SP, Brasil. 

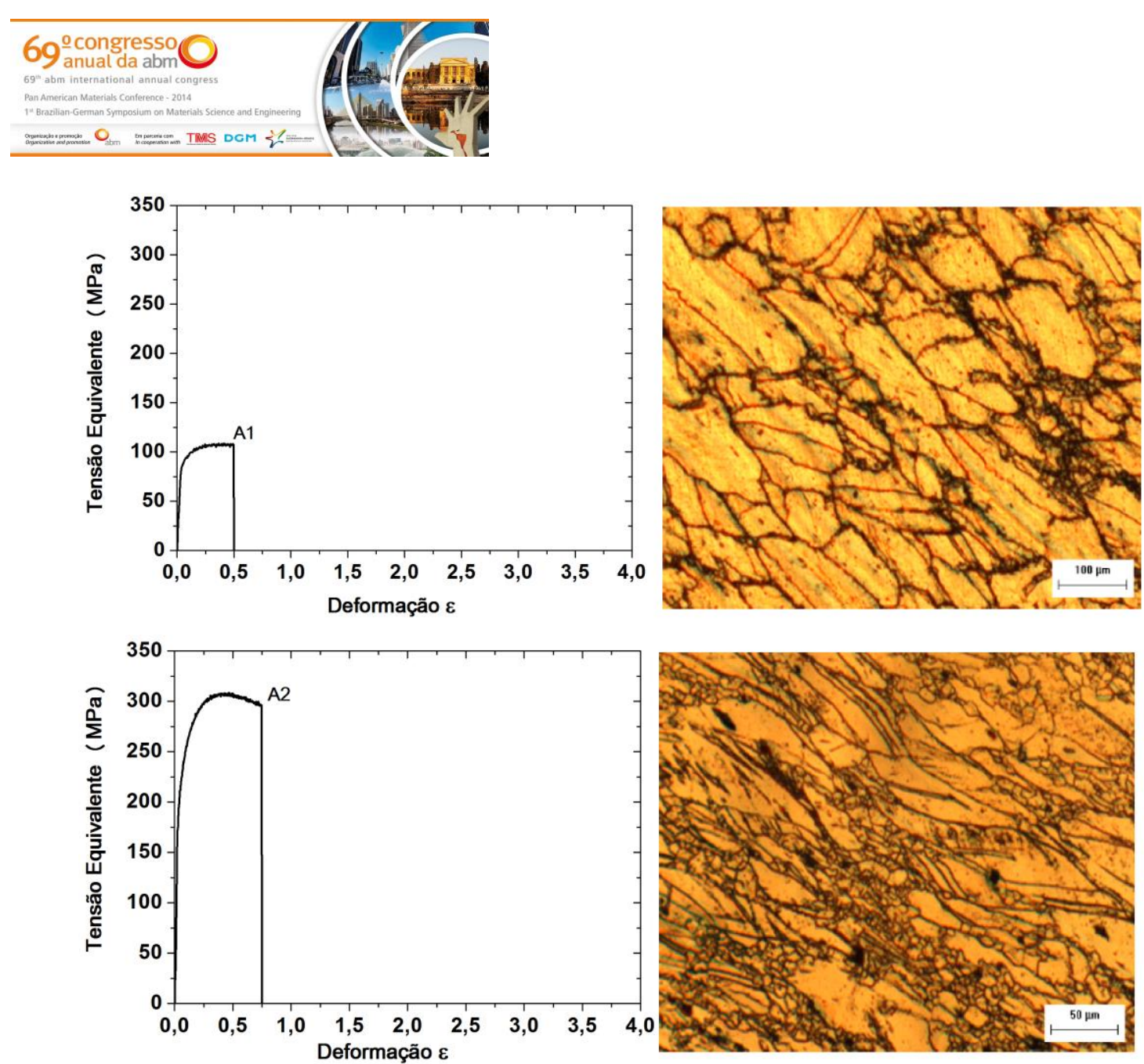

(a)
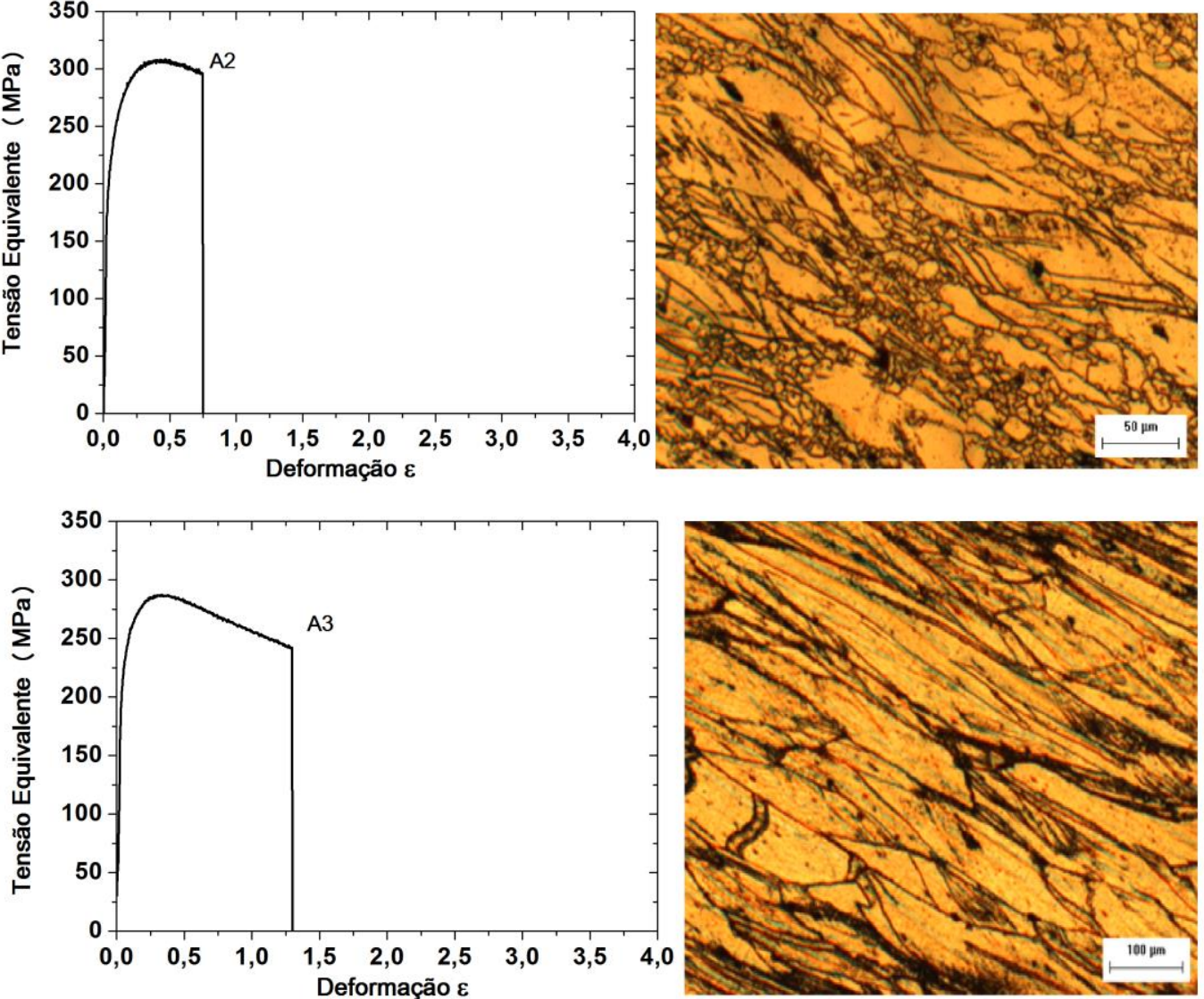

(b)
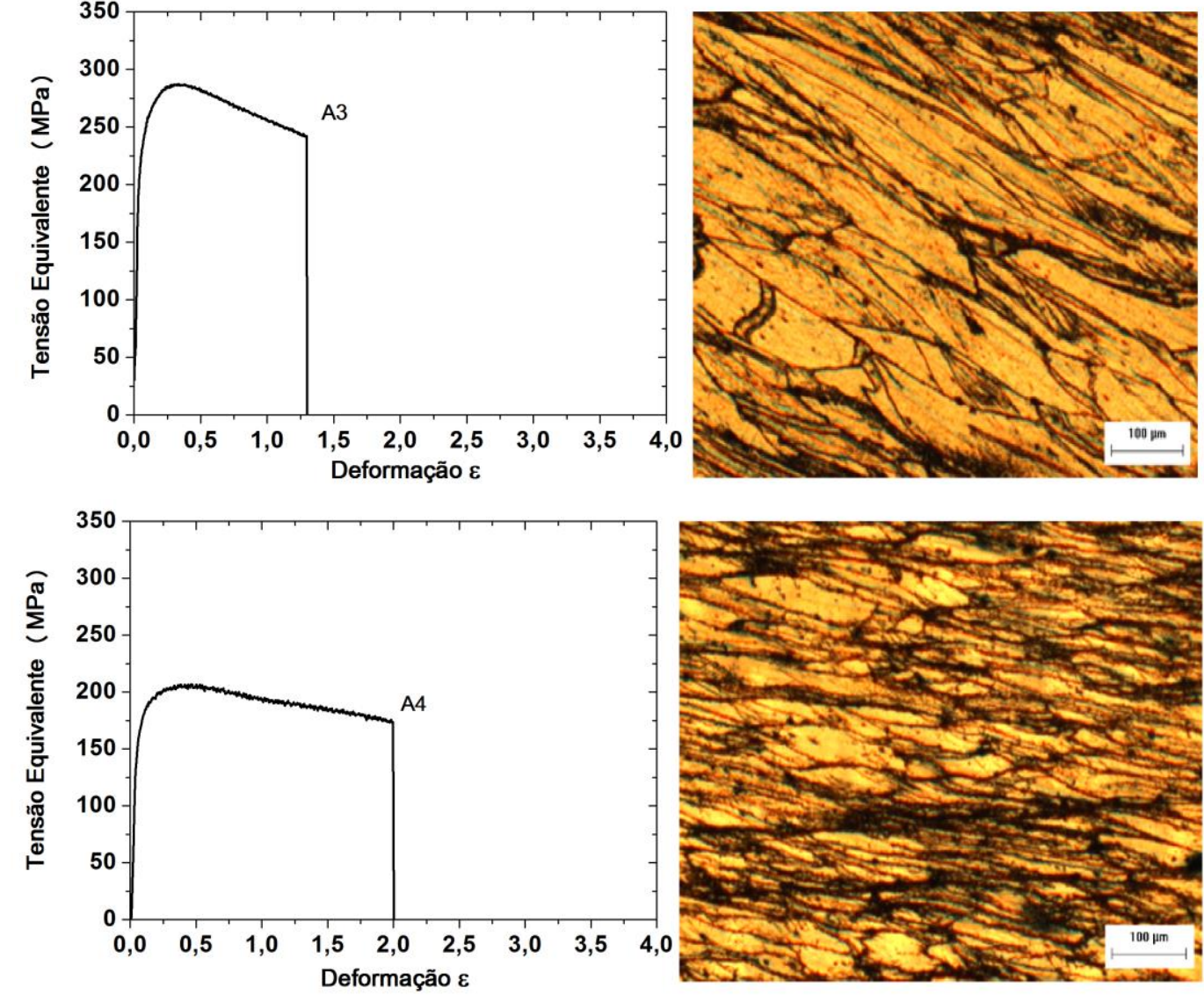

(c)

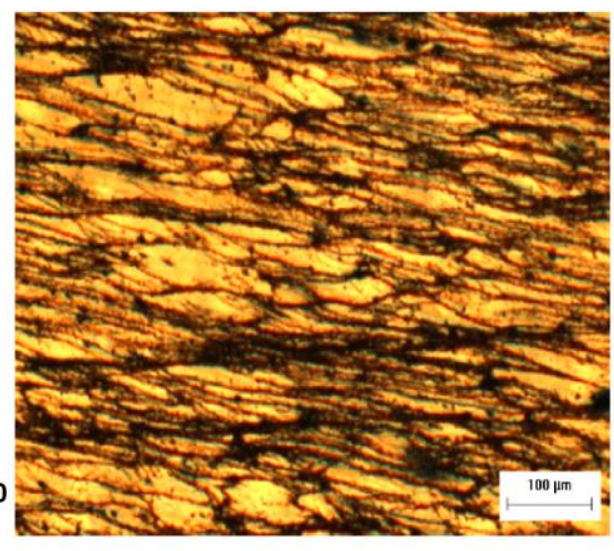

(d)

Figura 4. Microestrutura das amostras do aço ISO 5832-9 deformada nas condições de instabilidade plástica A1, A2, A3 e A4.

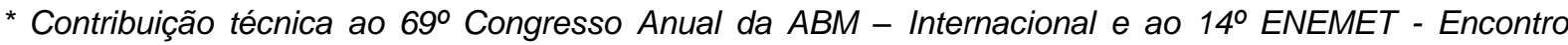
Nacional de Estudantes de Engenharia Metalúrgica, de Materiais e de Minas, 21 a 25 de julho de 2014, São Paulo, SP, Brasil. 


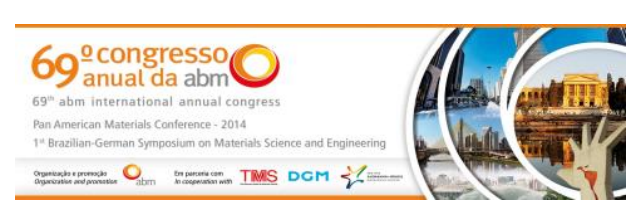

segundo conjunto de condições, fora da região de instabilidade, A5 $\left(1050^{\circ} \mathrm{C} /\right.$ $\left.0,5 \mathrm{~s}^{-1}\right)$ e $\mathrm{A} 6\left(1200^{\circ} \mathrm{C} / 1 \mathrm{~s}^{-1}\right)$, as curvas de escoamento plástico encontram-se num estágio estacionário de tensão e o desenvolvimento da recristalização dinâmica com formação em colar, Figura 5. Nota-se que a microestrutura se apresenta fortemente deformada com grãos alongados em forma de panquecas com intensa recuperação dinâmica e o surgimento de alguns contornos de grão serrilhados gerando os primeiros grãos recristalizados dinamicamente ao longo de contornos decorrente da dependência da mobilidade das discordâncias com as condições de deformação e EFE. Em níveis elevados de deformação o material encontra-se bastante recristalizado, como observado por Sousa, R.C [14] por análise de MEV/EBSD, onde mais de $90 \%$ da microestrutura estava recristalizada nessas condições. Porém mantendo ainda a presença de grãos pré-existentes deformados com atraso na cinética de recristalização dinâmica. A microestrutura na deformação máxima aplicada de 4,0, maior que a deformação de estado estacionário, possui ainda alguns grãos pré-existentes deformados e apresenta o tamanho médio de grãos recristalizados maior com recristalização dinâmica retardada, Figura 5a. Como consequência do atraso na recristalização dinâmica, o processo de restauração promovido pela recuperação dinâmica com a deformação minimiza a energia armazenada o que justifica a formação em colar sugerindo uma taxa de nucleação baixa com recristalização dinâmica parcial.
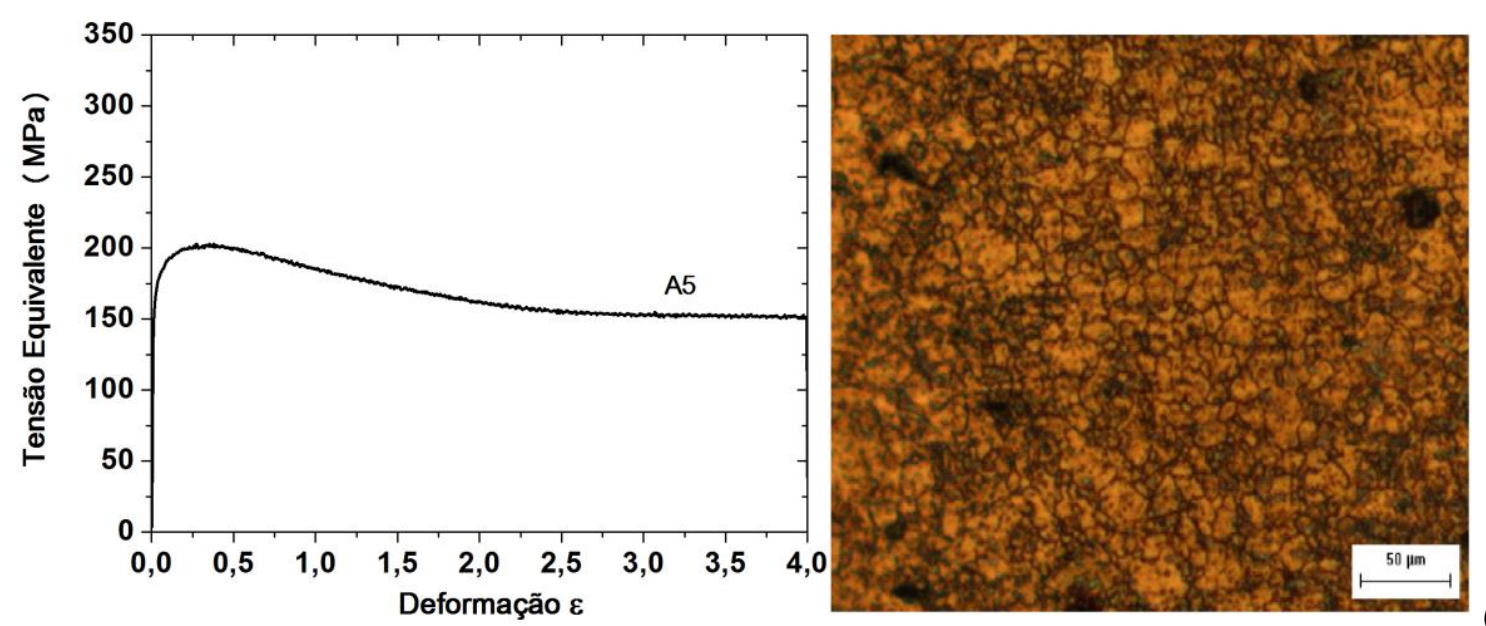

(a)
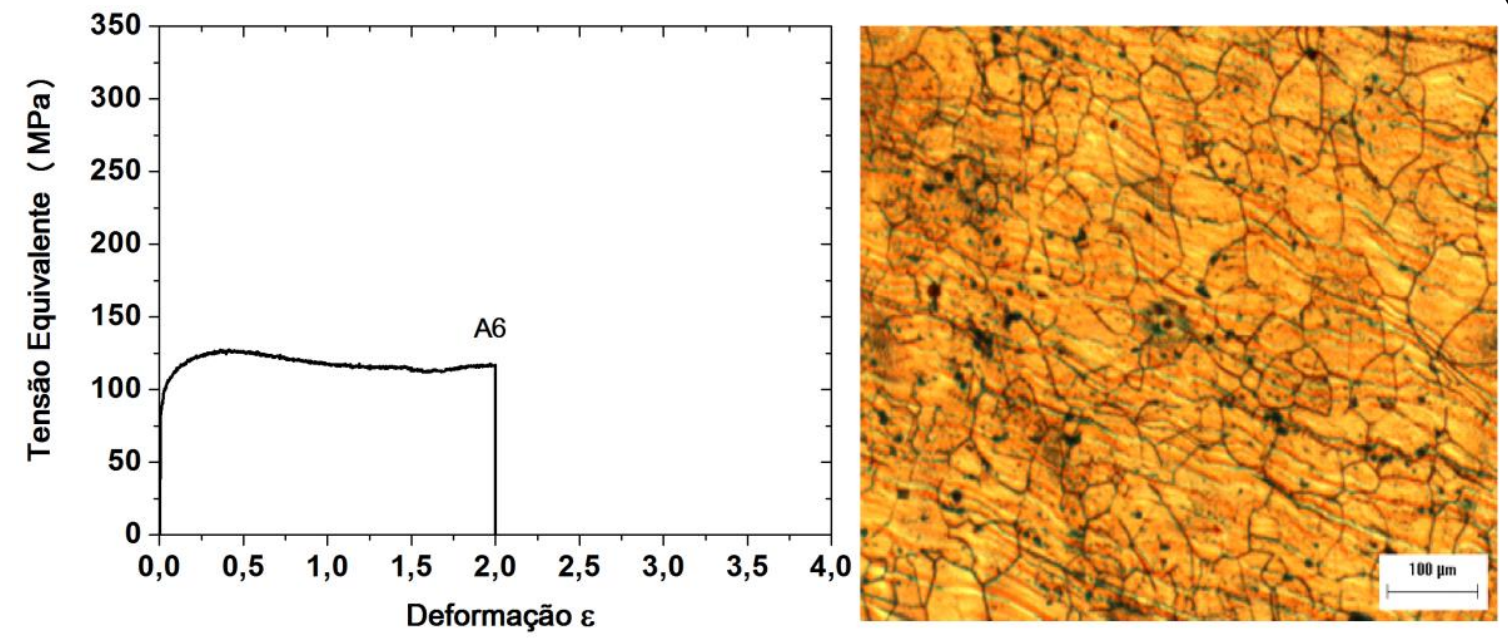

(b)

Figura 5. Microestrutura das amostras do aço ISO 5832-9 deformada nas condições de instabilidade plástica A5 e A6.

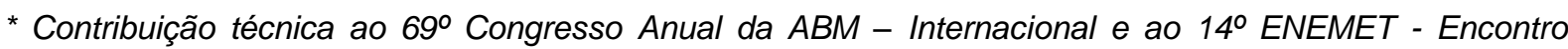
Nacional de Estudantes de Engenharia Metalúrgica, de Materiais e de Minas, 21 a 25 de julho de 2014, São Paulo, SP, Brasil. 


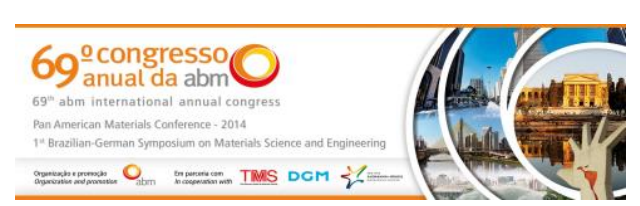

Por fim na condição A7 $\left(1050{ }^{\circ} \mathrm{C} / 0,1 \mathrm{~s}^{-1} / 4,0\right)$, Figura 6 , nota-se que as microestruturas obtidas apresentam algum serrilhamento nos contornos de grãos, a nucleação preferencialmente em contornos não é observada, pelo menos de forma clara como nas microestruturas anteriores, sugerindo que esta pode ocorrer de modo convencional, ou seja, com a nucleação tanto nos contornos quanto dentro dos grãos. Em deformações maiores nota-se alguns contornos de grãos serrilhados, sendo o número desses contornos maior com predominância do alongamento e para a deformações maiores a microestrutura se encontra quase totalmente recristalizada, visto que existem ainda alguns grãos pré-existentes deformados, confirmando que não há homogeneidade no processo de recristalização.
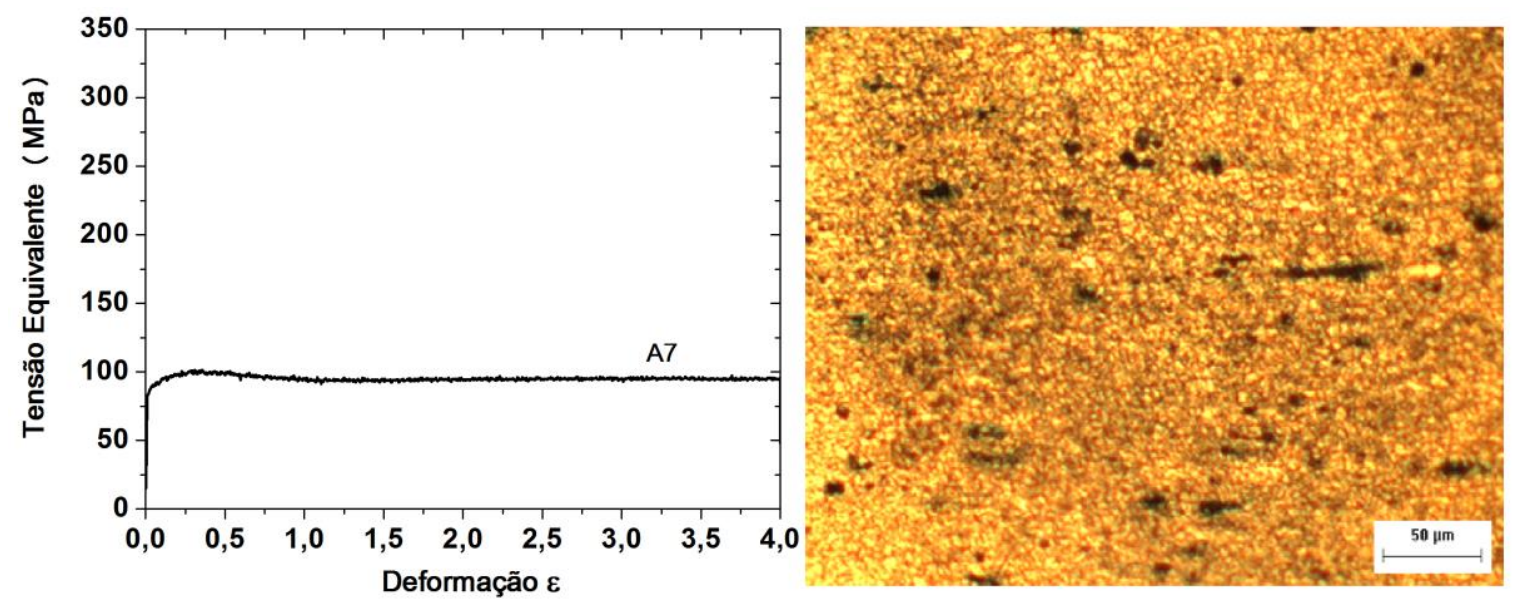

Figura 6. Microestrutura das amostras do aço ISO 5832-9 deformada nas condições de estabilidade plástica A7.

Nesse estágio de estado estacionário, nota-se que o tamanho médio de grãos DRX medido segundo a Norma E-112 para as condições $A 5$, A6 e A7, são respectivamente $6,0 \mu \mathrm{m}, 20 \mu \mathrm{m}$ e $5,0 \mu \mathrm{m}$ valores menores que o tamanho de grão inicial de $68 \mu \mathrm{m}$, desde que o tamanho de grão médio diminui para temperaturas menores. O resultado da recristalização dinâmica é a substituição de uma microestrutura de grão inicialmente de tamanho grande para uma consideravelmente mais fina. Este refino de grão resulta da presença de partículas de precipitados da fase $Z$ e do nitrogênio em solução sólida responsável pelos altos níveis de resistência mecânica alcançado nos ensaios.

Nota-se também que quanto menor o tamanho de grão austenitico menor o tempo necessário para a formação de pites de corrosão, visto que a profundidade dos contornos de grãos permite maior mobilidade difusional de cromo e também suas distâncias difusionais no interior dos grãos são menores, onde ambas os fatores facilitam a reposição de cromo nas regiões empobrecidas dos contornos.

\subsection{Análise dos Ensaios Eletroquímicos}

\subsubsection{Potencial de circuito aberto}

As curvas da variação do potencial de corrosão em função do tempo de imersão a temperatura ambiente do aço ISO 5832-9 são apresentados nas Figuras 7a-b. Os resultados mostraram que após 30 min de imersão em solução 0,9 \% de $\mathrm{NaCl}$ todas as amostras haviam atingido a estabilização do potencial, sem variação no início dos ensaios. Porém à medida que o tempo de imersão aumenta nota-se valores

* Contribuição técnica ao 69ํ Congresso Anual da ABM - Internacional e ao 14 ENEMET - Encontro Nacional de Estudantes de Engenharia Metalúrgica, de Materiais e de Minas, 21 a 25 de julho de 2014, São Paulo, SP, Brasil. 


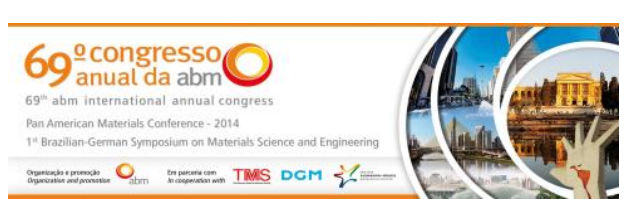

próximos do potencial de corrosão $\left(\mathrm{E}_{\mathrm{ca}}=0,3 \mathrm{mV}\right)$ para as amostras em ambas as regiões definindo a queda da passividade do material pela nucleação e propagação estável de pites de corrosão, assinalado por um aumento na densidade de corrente de corrosão, numa pequena região da superfície do material.
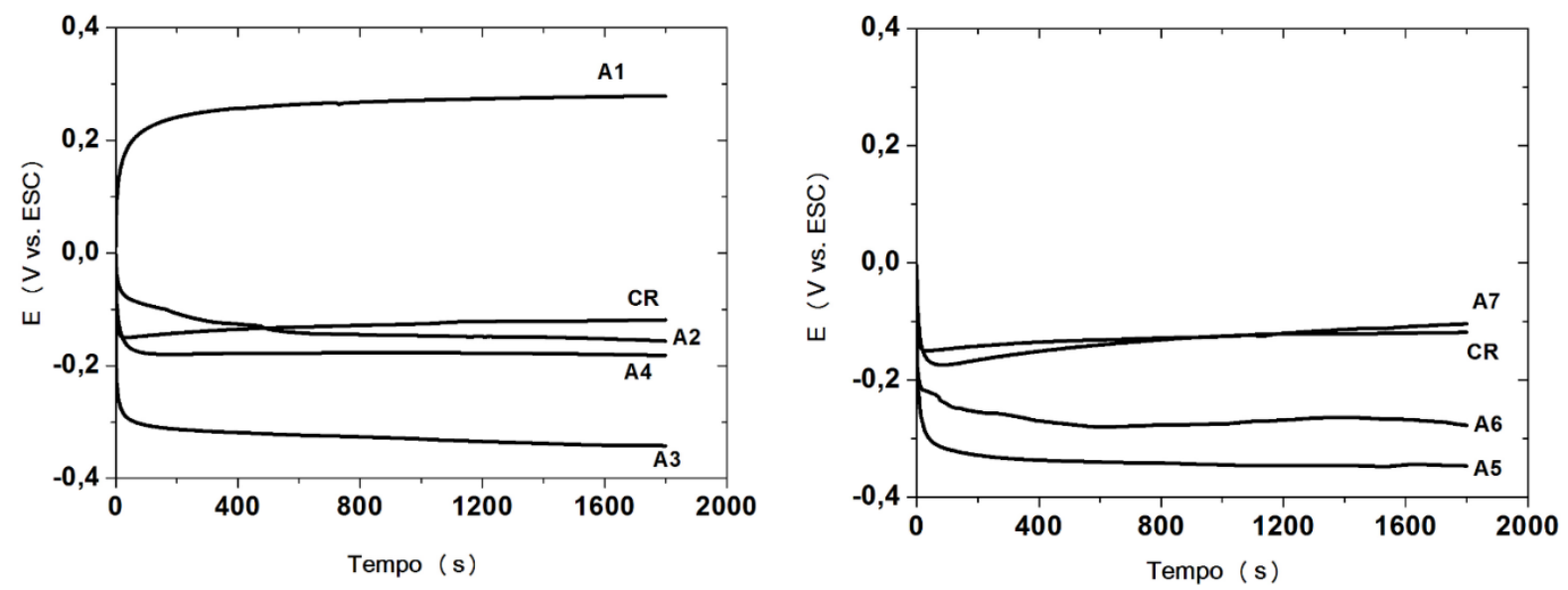

Figura 7. Variação do potencial de corrosão em função do tempo de imersão para as amostras na região de instabilidade plástica, $A 1, A 2, A 3, A 4$ e A5.

Outra forma de se avaliar este efeito é através do cálculo do Conteúdo Efetivo de Cromo (Creff) para o aço ISO 5832-9 é de 23, sendo um indicativo da atividade de cromo entre a interface carbeto e matriz, onde este elevado valor resulta num baixo empobrecimento de cromo nos contornos de grãos, indicando um período mais longo para ocorrência da formação de pites (sensitização) com forte influência do nitrogênio. Nota-se também que os teores de $\mathrm{Cr}$, Mo e $\mathrm{N}$ garantem um valor de resistência a corrosão por pite elevado, com PRE calculado de 53, maior que o valor calculado para o ASTM $F$ 138, PRE $=32$, o que sugere uma maior resistência a corrosão localizada desta liga.

Vê-se ainda que na curva para a condição A1 a estabilização desenvolve-se de maneira coerente, com baixa variação da declividade em direção a um potencial mais nobre, com tendência à formação da camada passiva no eletrólito. $O$ fato das curvas $A 2$ à $A 6$ se desenvolverem com potenciais menores sinaliza a dissolução do filme no meio eletrolítico, gerando diminuição do potencial em função do tempo do ensaio, com perda da camada passiva no material favorecendo uma convergência à corrosão nessa condição.

\subsubsection{Espectroscopia de impedância eletroquímica}

Os ensaios de espectroscopia de impedância eletroquímica (EIE) obtidos para as amostras nas regiões de instabilidade e estabilidade plástica do aço ISO 5832-9 apresentaram similaridades com os resultados obtidos dos gráficos de potencial de circuito aberto com mesma tendência perante a resistência à corrosão por método de Bote, com as amostras nas condições A3 e A5 apresentando menor inclinação das retas, Figura 8. Já as amostras A1 e A7 apresentaram inclinação marcante em seus respectivos gráficos oferecendo assim uma maior tendência à resistência a corrosão. Este fato observado nas amostras A3 e A5, Figura 8, que apresentaram os menores ângulos de fase indicando uma tendência a menor proteção do material. Entretanto, a amostras A1 apresentou um dos maiores ângulos e A7 o maior ângulo de fase indicando a uma maior tendência à resistência a corrosão. De maneira geral as amostras A2, A4, A5 e A6 apresentaram condições intermediárias em relação às

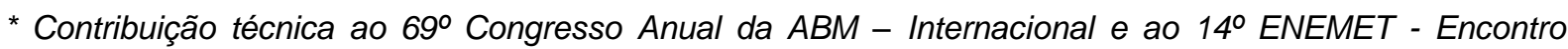
Nacional de Estudantes de Engenharia Metalúrgica, de Materiais e de Minas, 21 a 25 de julho de 2014, São Paulo, SP, Brasil. 
demais, com maior tendência à proteção em relação à amostra como recebida. Nota-se também que a condição da amostra A7 apresenta a melhor tendência a proteção a corrosão dentre todas as amostras.
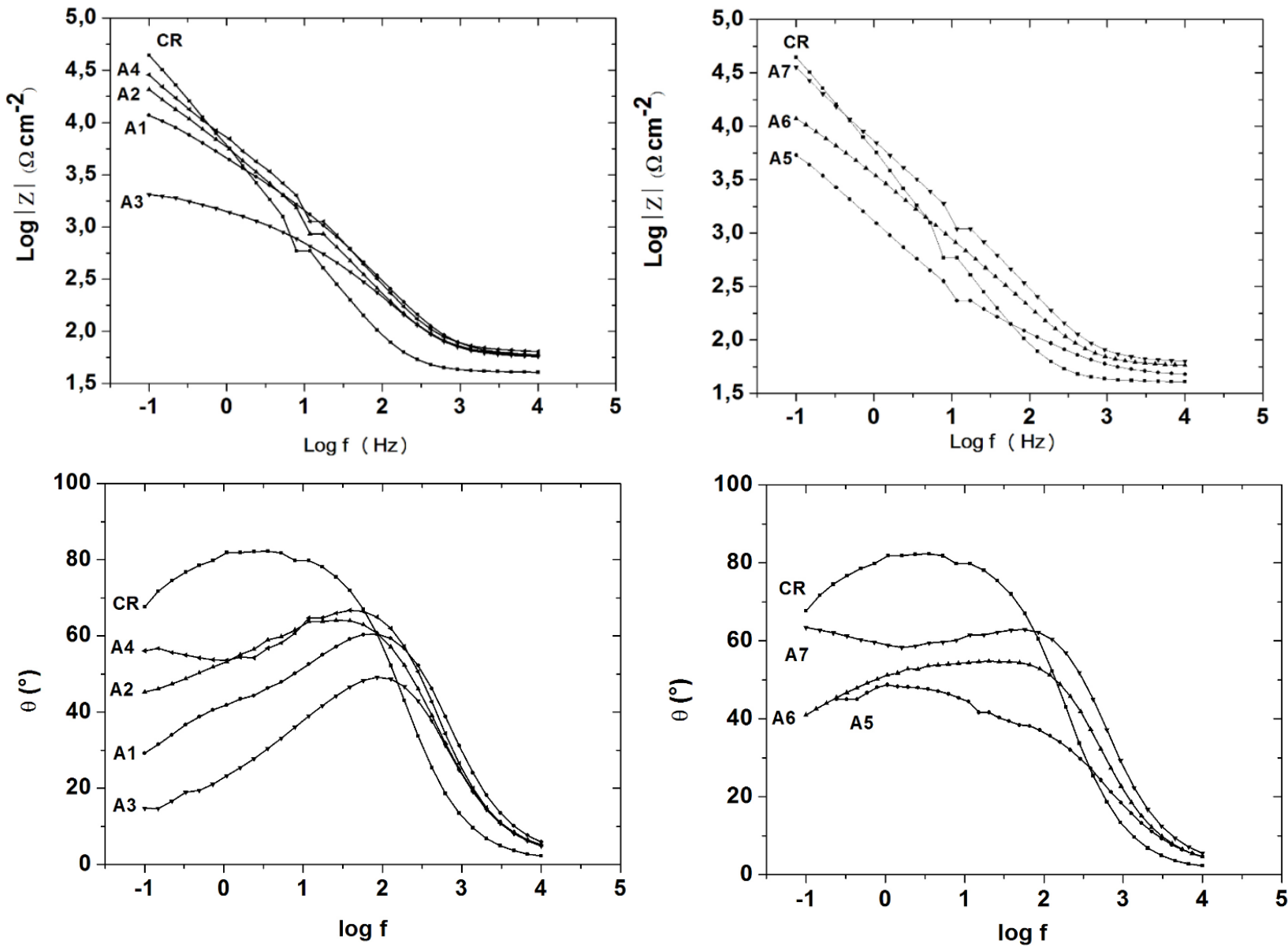

Figura 8. Diagrama de Bode obtidos para as amostras A1 e A7. a) Variação do log IZI VS. log f; b) Variação do $\theta$ vs. $\log f$.

Através do diagrama de Nyquist, Figura 9, nota-se a formação de um único processo com arco capacitivo referente à transferência de carga na dupla camada elétrica. Com o passar do tempo, o filme fica mais resistente e o arco não se completa nesta região de análise. Na Figura 8 nota-se que os resultados obtidos pelos diagramas de Bode são correspondentes aos diagramas de Nyquist, onde as amostras nas condições A3 e A5 apresentaram a maior tendência a formação de um arco, evidenciando uma menor resistência à corrosão para essas duas amostras dentro de suas respectivas regiões, e a amostra A7 apresentou a menor tendência a formação do arco capacitivo evidenciando maior proteção a corrosão das amostras estudadas.

* Contribuição técnica ao 69ํㅡㄹ Congresso Anual da ABM - Internacional e ao 14ํ ENEMET - Encontro Nacional de Estudantes de Engenharia Metalúrgica, de Materiais e de Minas, 21 a 25 de julho de 2014, São Paulo, SP, Brasil. 

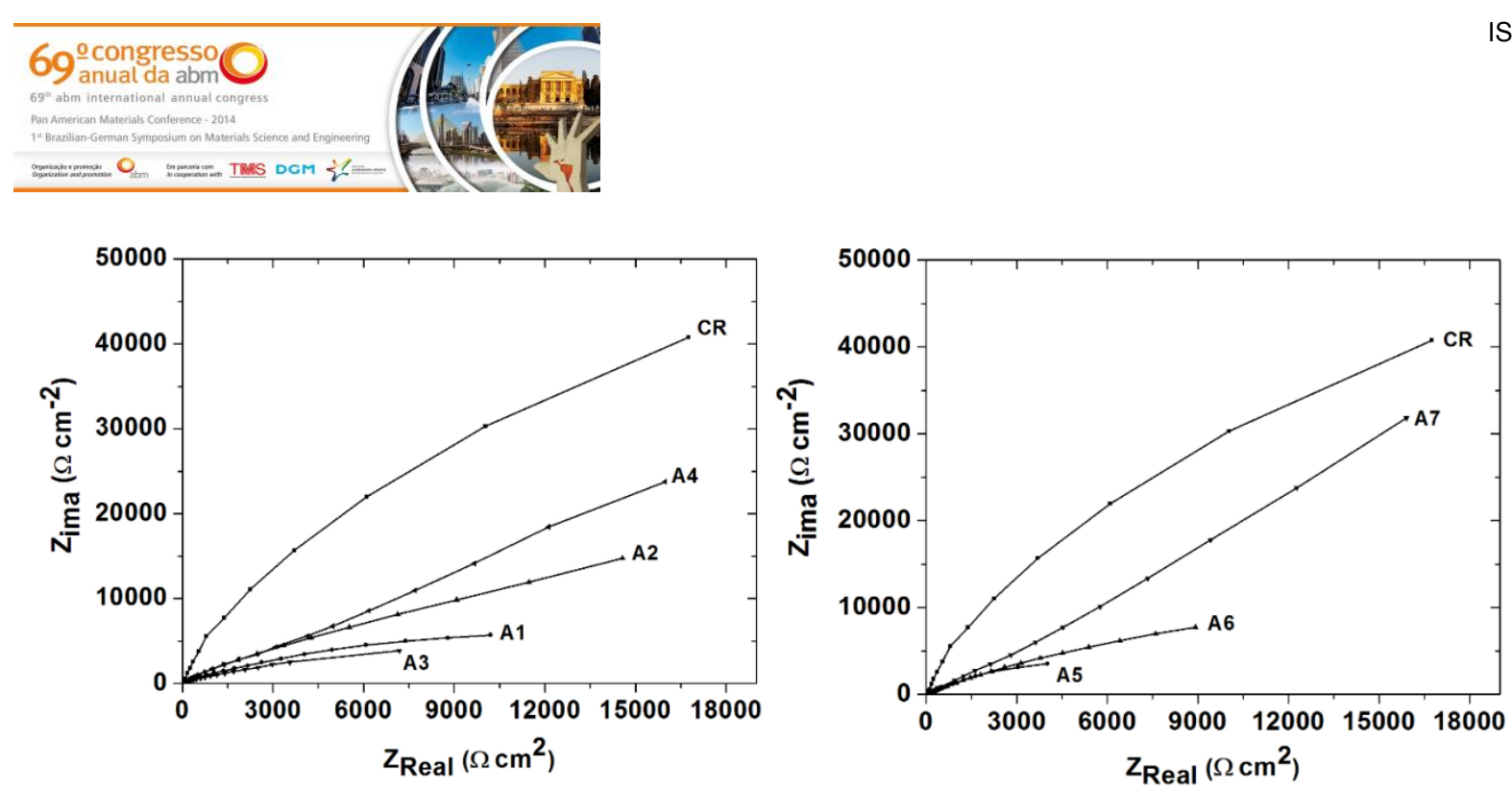

Figura 9. Diagramas de Nyquist obtidos para as amostras: (a) região de instabilidade plástica, A1, A2, A3, A4 e A5, (b). fora da região de instabilidade plástica, A6, A7, e A8.

Nota-se que tanto no diagrama de Bode quanto no de Nyquist, verifica-se que há uma similaridade nos resultados obtidos nos três tipos de gráficos, onde se percebe que existe uma diferença desfavorável das regiões de instabilidade plástica em relação a amostra como recebida. A partir da análise dos diagramas de EIE, permite-se afirmar que a amostras $A 7$ apresentou os melhores resultados frente à proteção à corrosão tanto nos diagramas de Bode quanto no de Nyquist. Onde a maior resistência a corrosão do aço nas condições de boa trabalhabilidade é atribuído ao aumento da estabilidade do filme passivo, favorecido provavelmente pela presença de nitrogênio em solução sólida intersticial, aferindo maior estabilidade química e mecânica. Já as amostras A3 e A5 exibiram as piores respostas frente à proteção de corrosão nas suas respectivas regiões, considerando os valores experimentais obtidos em termos do módulo de impedância.

\subsubsection{Polarização cíclica potenciodinâmica}

Os ensaios de polarização cíclica potenciodinâmica foram realizados com o intuito de se obter informações sobre a resistência à corrosão, Figura 10, verificando se há estabilidade da camada sobre a superfície do aço. Vê-se que a extrapolação de Tafel nos gráficos exibe que a amostra como recebida (CR) apresenta potencial mais nobre entre todas as amostras. Dentre as condições estudadas as amostras A1 e A7 foram as que apresentaram o potencial mais nobre nos domínios considerados, evidenciando uma melhor resistência à corrosão em relação às demais, atribuído ao aumento da estabilidade do filme passivo favorecido pela presença do nitrogênio em solução sólida intersticial na matriz que melhora a resistência mecânica nessa liga devido a sua eficiência em produzir o endurecimento por solução sólida, promovendo diminuição da EFE com aumento da eficiência dos contornos de grãos a movimentação de discordâncias e diminuição da difusividade do carbono o que leva ao retardo da precipitação de carbonetos e consequentemente reduz 0 fenômeno da sensitização, propiciando a formação de nitretos mais estáveis com aumento na resistência mecânica da liga.

Quanto às correntes de corrosão fica evidente que as amostras A1, A7 e CR apresentam as menores correntes de corrosão, respectivamente, fato que também demonstra boa resistência a corrosão para estas amostras. Já as amostras A3 e A5 apresentaram os menores potenciais de corrosão e maior corrente de corrosão caracterizando-se uma tendência maior a corrosão para suas respectivas regiões em relação às demais condições, concordante com os resultados obtidos nos outros

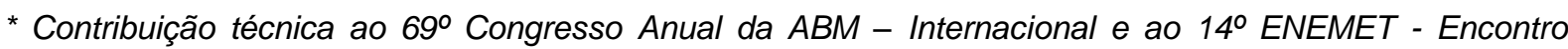
Nacional de Estudantes de Engenharia Metalúrgica, de Materiais e de Minas, 21 a 25 de julho de 2014, São Paulo, SP, Brasil. 


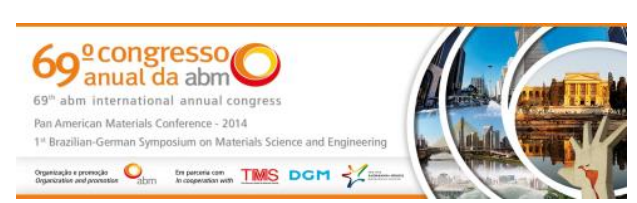

Tabela 3. Parâmetros levantados nos ensaios eletroquímicos pelo método da extrapolação de Tafel

\begin{tabular}{cccc}
\hline & $\mathbf{I}_{\text {corr }}(\boldsymbol{\mu} \mathbf{A})$ & $\mathbf{E}_{\text {corr }}(\mathbf{m V})$ & $\mathbf{T}_{\mathbf{c}}\left(\mathbf{m m . a n \mathbf { a n } ^ { - 1 } )}\right.$ \\
\hline CR & 0,106 & 0,366 & 0,001388 \\
A1 & 0,135 & 0,129 & 0,001768 \\
A2 & 0,178 & $-0,102$ & 0,002332 \\
A3 & 0,713 & $-0,314$ & 0,009339 \\
A4 & 0,471 & $-0,079$ & 0,006169 \\
A5 & 2,35 & $-0,23$ & 0,030781 \\
A6 & 0,959 & $-0,248$ & 0,012561 \\
A7 & 0,021 & 0,09 & 0,000275 \\
\hline
\end{tabular}

\section{CONCLUSÃO}

Os ensaios de torção a quente isotérmico contínuo mostram que a tensão de escoamento plástico é sensível aos parâmetros de deformação. O pico de tensão diminui com o aumento da temperatura e redução da taxa de deformação com alta taxa de recuperação dinâmica com grãos alongados, acúmulo de tensão e bandas de deformação, gerando regiões de fluxo localizado. Essas regiões de instabilidade plástica (amostras A2, A3, A4, A5 e A6) apresentam grau de corrosão maior em relação às amostras como - recebidas $(\mathrm{CR})$ atribuídas à redução da instabilidade do filme passivo. As regiões de alta temperatura e baixa taxa de deformação apresentam boa trabalhabilidade com microestrutura final refinada com grãos recristalizados dinamicamente de forma retardada sem evidencia de corrosão localizada, favorecida pela presença do nitrogênio em solução sólida.

\section{Agradecimentos}

Os autores agradecem a FAPEMA, CAPES e ao CNPq (Brasil) pelo apoio financeiro deste trabalho.

\section{REFERÊNCIAS}

1 Hench L, Polak J. Third Generation Biomedical Materials. Science. 2002;295:1014-17.

2 Giordani EJ, Jorge Jr. AM, Balancin O. Proportion of recovery and recrystallization during interpass times at high temperatures on a $\mathrm{Nb}$ - and $\mathrm{N}$-bearing austenitic stainless steel biomaterial. Scripta Materialia. 2006;55:743-746.

3 Giordani EJ, Jorge Jr. AM, Balancin O. Evidence of train induced precipitation on a $\mathrm{Nb}$ and N-Bearing austenitic stainless steel biomaterial. Mater. Sci. Forum. 2005;500501:179-186.

4 Yang K, Ren Y. Nickel-free austenitic stainless steels for medical applications. Sci. Technol. Adv. Mater. 2010;11.

5 Jocobs, J.J. Corrosion of metals orthopaedic implants: current concepts review. The Journal of Bone and Surgery. 1998;80A(2):268-282.

6 McQueen HJ. Development of Dynamic Recrystallization Theory. Materials Science and Engineerin A. 2004;387:203-208.

7 Sakai T, Jonas JJ. Dynamic Recrystallization: Mechanical and Microstructural Consideration. Acta Metallurgica. 1984;32:198-209.

8 Schramm RE, Reed RP. Stacking fault energies of seven commercial austenitic stainless steels. Metallurgical and Materials Transactions A. 1975;6A:1345.

* Contribuição técnica ao 69 Congresso Anual da ABM - Internacional e ao 14ํㅡㄹ ENET - Encontro Nacional de Estudantes de Engenharia Metalúrgica, de Materiais e de Minas, 21 a 25 de julho de 2014, São Paulo, SP, Brasil. 
9 Wahabi ME, Gavard L, Montheillet F, Cabrera JM, Prado JM. Effect of initial grain size on dynamic recrystallization in high purity austenitic stainless steels. Acta Materialia. 2005;53:4605-12.

10 Ziegler H. Progress in Solid Mechanics. v. 4. eds.: Sneddon IN, Hill R. New York: John Wiley and Sons; 1963. p.93.

11 Prasad YVRK, Sasidhara S. Hot working guide: a compendium of processing maps. ASM International. Materials Park; 1997.

12 Venugopol S, Sivaprad PVA. Journey With Prasad's Processing Maps. Journal of Materials Engineering and Performance. 2003;12(6):675.

13 Santos ES, Sousa RC, Jorge Jr. AM, Balancin O. Hot deformation behavior of an Nband $\mathrm{N}$ - bearing austenitic stainless steel biomaterial. Materials Science and Engineering A. 2012.

14 Sousa RC, Santos ES, Jorge Jr. AM, Balancin O. Dynamic recovery and dynamic recrysrallization competition on a $\mathrm{Nb}$ - and $\mathrm{N}$-bearing austenitic stainless steel biomaterial: Influence of strain rate and temperature. Materials Science and Engineering A. 2013.

* Contribuição técnica ao 69ํㅡㄹ Congresso Anual da ABM - Internacional e ao 14ํㅡㄹ ENEMET - Encontro Nacional de Estudantes de Engenharia Metalúrgica, de Materiais e de Minas, 21 a 25 de julho de 2014, São Paulo, SP, Brasil. 